http://dx.doi.org/10.4322/pmd.2013.005

\title{
Steps for requirements writing
}

\author{
Cláudio Fogaça Truyts ${ }^{a}$ Daniel Alves Simão de Limaa ${ }^{a}$ Fabricio Ziliotti Damico ${ }^{b}$, \\ Felipe Motta ${ }^{a}$, Luciano Tomassoni Coelho ${ }^{a}$, Ricardo Franco ${ }^{a}$ \\ वIAE Instituto de Aeronáutica e Espaço (Institute of Aeronautics and Space) \\ bNAVCON Navegação e Controle
}

e-mails: ctruyts@hotmail.com; daniel.sj..iae@gmail.com; fzdamico@yahoo.com.br; felipedamotta@gmail.com; tomassoni@iae.cta.br; ricardor@@iae.cta.br

\begin{abstract}
This article presents an overview of the advantages of using Systems Engineering techniques to a product or an organization development, from the moment of its conception to its disposal. The Section 1 describes the work of a Systems Engineer in a project description, in other words, the project objectives identification, the techniques and tools that should be used and how simple and clear the requirements should be. The Section 2 presents the project stakeholders, who are the actors or organizations that contribute actively or passively, positively or negatively to the project, and the responsibility of the Systems Engineer, who must identify the stakeholders needs and provide one or more engineering solutions to meet these needs during the project lifecycle. The Section 3 discusses the quality of the requirements. Once identified the needs of the stakeholders, each one generates one or more requirements which must be written so as to be clear, concise and complete. Section 4 shows several engineering models which can be used on the process, such as: V model, Evolutionary model and Spiral model. Section 5 presents techniques used to identify the essential functions of the project from the requirements of stakeholders, and implement it by different architectures. The Section 6 shows that we can obtain alternatives of hardware and software implementations from physical architectures, closing the Systems Engineering process. The conclusion will present the skills or prerequisites that a Systems Engineer must have in order to perform his role, including qualified technical knowledge, human relationships, balance in the division of objectives, and others.
\end{abstract}

Keywords: systems engineering models, systems engineer, requirements, project, stakeholders.

\section{Introduction}

Systems Engineering (INTERNATIONAL..., 2011) is

[...] an interdisciplinary approach and means to enable the realization of successful systems. It focuses on defining customer needs and required functionalities early in the development cycle, documenting requirements, and then proceeding with design synthesis and system validation while considering the complete problem [...].

so the Systems Engineer should be able to develop a set of requirements which will be the basis for the project implementation in an organization using appropriate techniques, achieved through a structured analysis of all the needs obtained through stakeholder. The greater the number of the needs identified, the better the solution for the problem offered by the Systems Engineer. Importantly, in most cases, stakeholders are not able to externalize their goals on the project, so the biggest task of the Systems Engineer is to write in the form of the requirements, the real objectives of the stakeholders. For that he can use various ways such as surveys, questionnaires, meetings and personal observations on similar projects.

To carry out a project, the Systems Engineer must develop nontrivial skills, such as: capture requirements obtained from people or groups of people who are directly or indirectly involved in the project, identification and classification of these needs into relevant groups, since needs may differ, increasing the difficulty of the project implementation.

The Systems Engineer must also be able to balance these needs; and must have the ability to remove, group, sort and prioritize things in order to get to the end of the process, a detailed enough project objectives description, so the project can be implemented.

The more comprehensive the description captured by the Systems Engineer is, the greater the chance of the project becoming viable, because it will satisfy most of people involved.

The Systems Engineer must write the necessary requirements, from the description of the project objectives, to obtain these goals.

Requirements must be Necessary, Concise, Implementation Free, Attainable, Complete, Consistent, Unambiguous, and Verifiable and must have a Standard Construction, as described in Article "Characteristics of Good Requirement".

This article presents an overview of the advantages of using Systems Engineering techniques to a product or an organization development, from the moment of its conception to its disposal. 


\section{Stakeholders}

According to PMBOK (PROJECT..., 2008, p. 23) the definition of stakeholder is:

Person or organization (e.g., customer, sponsor, performing organization, or the public) that is actively involved in the project, or whose interests may be positively or negatively affected by execution or completion of the project. A stakeholder may also exert influence over the project or it deliverables.

Those involved in the project, identified by stakeholders, are people or groups of people, associations, government agencies, enterprises, and finally all people contributing in some way to the realization or not of the project. It is the role of the Systems Engineer to identify the most possible number of stakeholders and qualify them, in an attempt to minimize the project negative impact on society and to satisfy the costumers, or in other words, to satisfy all stakeholders in a balanced way.

Example: A construction of a hydroelectric plant will impact the first inhabitants of the region where a dam will be erected, followed by the environmental agencies, local government, workers, equipment providers, traffic engineering, so it can be seen that many stakeholders can be listed.

Another important concept is the lifecycle of the project, because there are stakeholders who will influence the project at the beginning of it, others will influence during the entire life cycle and others only at the end of the lifecycle, mainly at the discharge phase.

The Systems Engineer must have the ability to classify stakeholders, prioritize them, group them and thus implement the project (KELLER; KIRKWOOD; JONES, 2010).

\section{Requirements}

The requirements obtained from the capture of the stakeholders needs, seen in Section 2, must be, as previously mentioned, Necessary, Concise, Implementation Free, Attainable, Complete, Consistent, Unambiguous, Verifiable and must have an Standard Construction, or in other way, something simple, clear, concise, complete, easy to understand and evaluable.

Requirements should describe the needs and the way we could measure the effectiveness of this need.

Example: For the dam, one of the requirements could be: $100 \%$ of the wild animals that inhabit the region of the dam must be removed and delivered to the designated environmental protection group.

The Measure of Effectiveness of this Requirement is:

- $100 \%$ of wild animals moved $=$ excellent;

- $95 \%$ or more of wild animals moved = good;

- $85 \%$ to $95 \%$ of wild animals moved $=$ acceptable.

\section{Systems engineering models}

The Systems Engineering method is applied successively at different levels of design with the aim of obtaining the greatest possible number of requirements for project implementation and is applied up to the specific disciplinary method is more efficient than the Systems Engineering method, in this point the specific disciplinary method is used to develop the component or subsystem.

Thus, there are several engineering models for developing an implementation plan for the project; some of them will be showed in the following.

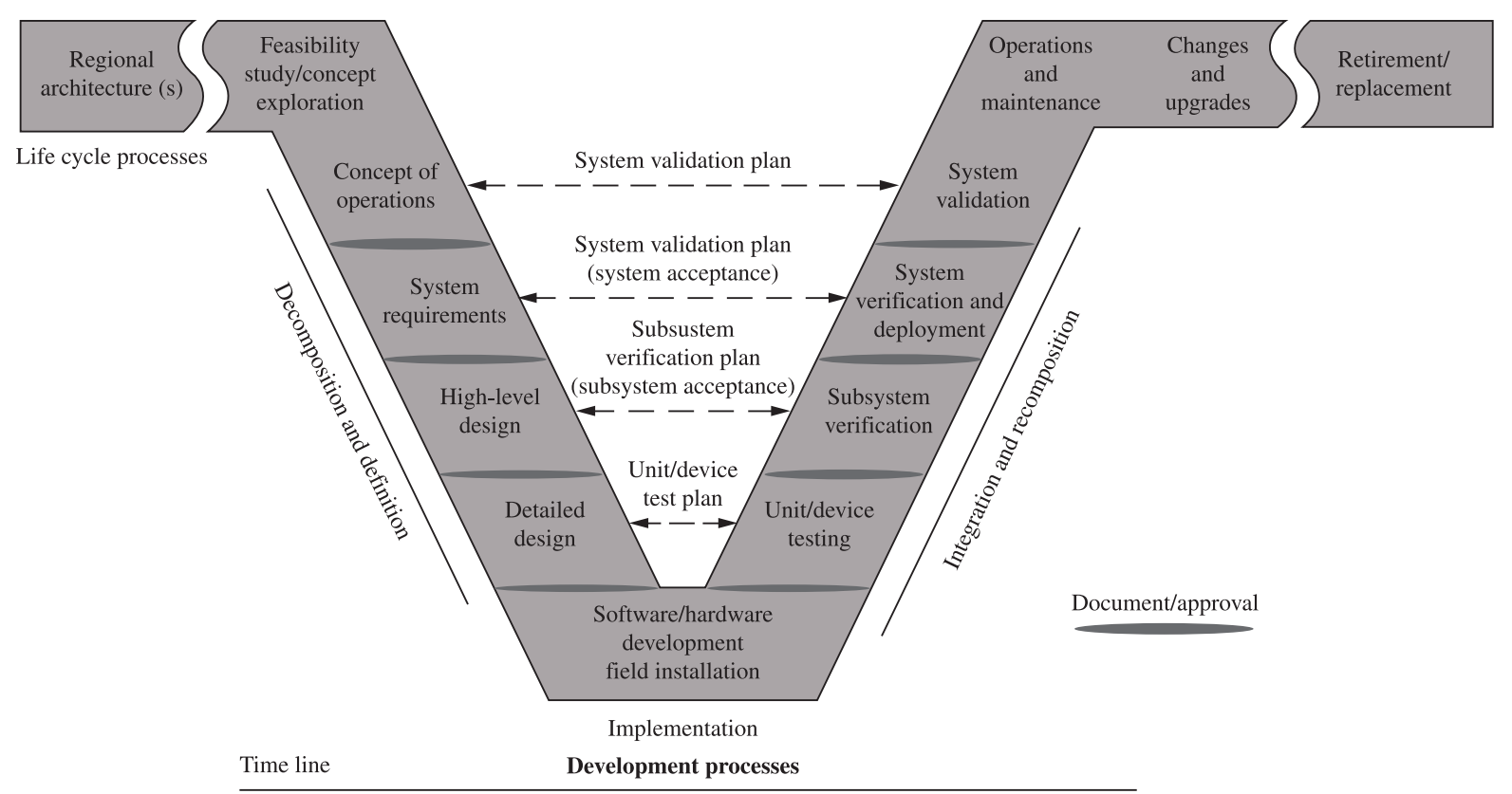

Figure 1. Model V diagram - Source: Kar and Bailey (1996). 


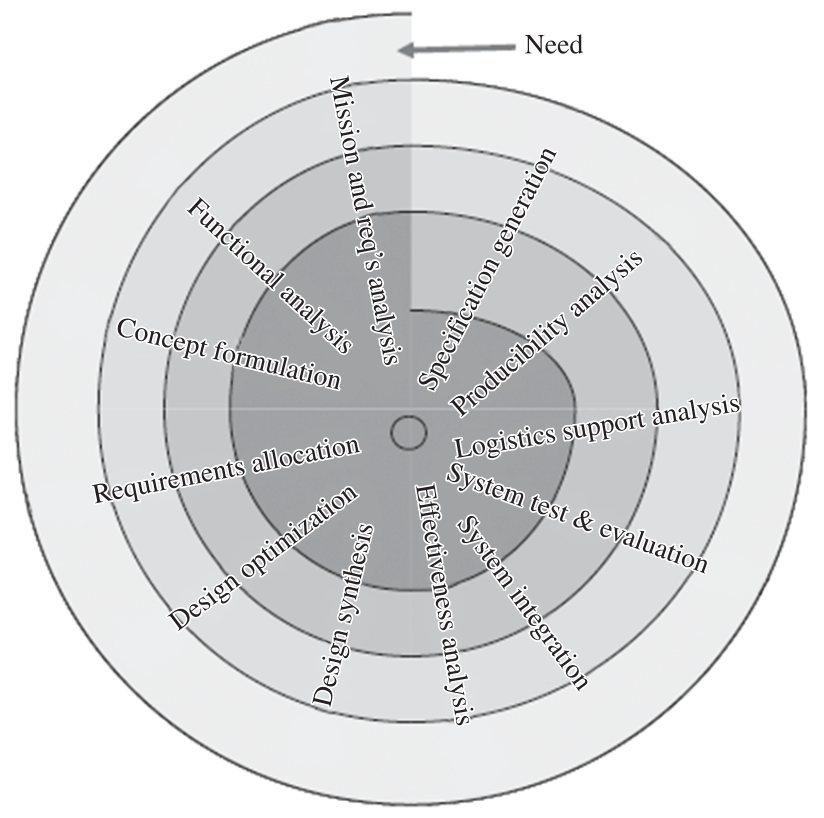

One of the engineering models is the Model V. After identify the objectives, stakeholders and write project requirements, the Systems Engineer must initiate a series of measures of effectiveness and performance, MOEs and MOPs, which will be used to evaluate the various stages of the project, as can be seen in the Model V diagram, Figure 1.

Another model widely used is the Spiral Model, where the Systems Engineer identifies goals, means, and measures and verifies, successively in all levels of planning, it is showed in Figure 2.

Other models may also be used, including: evolutionary model, model number, etc. See Figure 3.

Once established the engineering model and the measures of effectiveness and performance, the next work to be performed by the Systems Engineer is to define the physical architecture of the project. For this, he must deploy goals in functions that the project must accomplish to achieve its goals.

Figure 2. Spiral Diagram - Source: Kar and Bailey (1996).
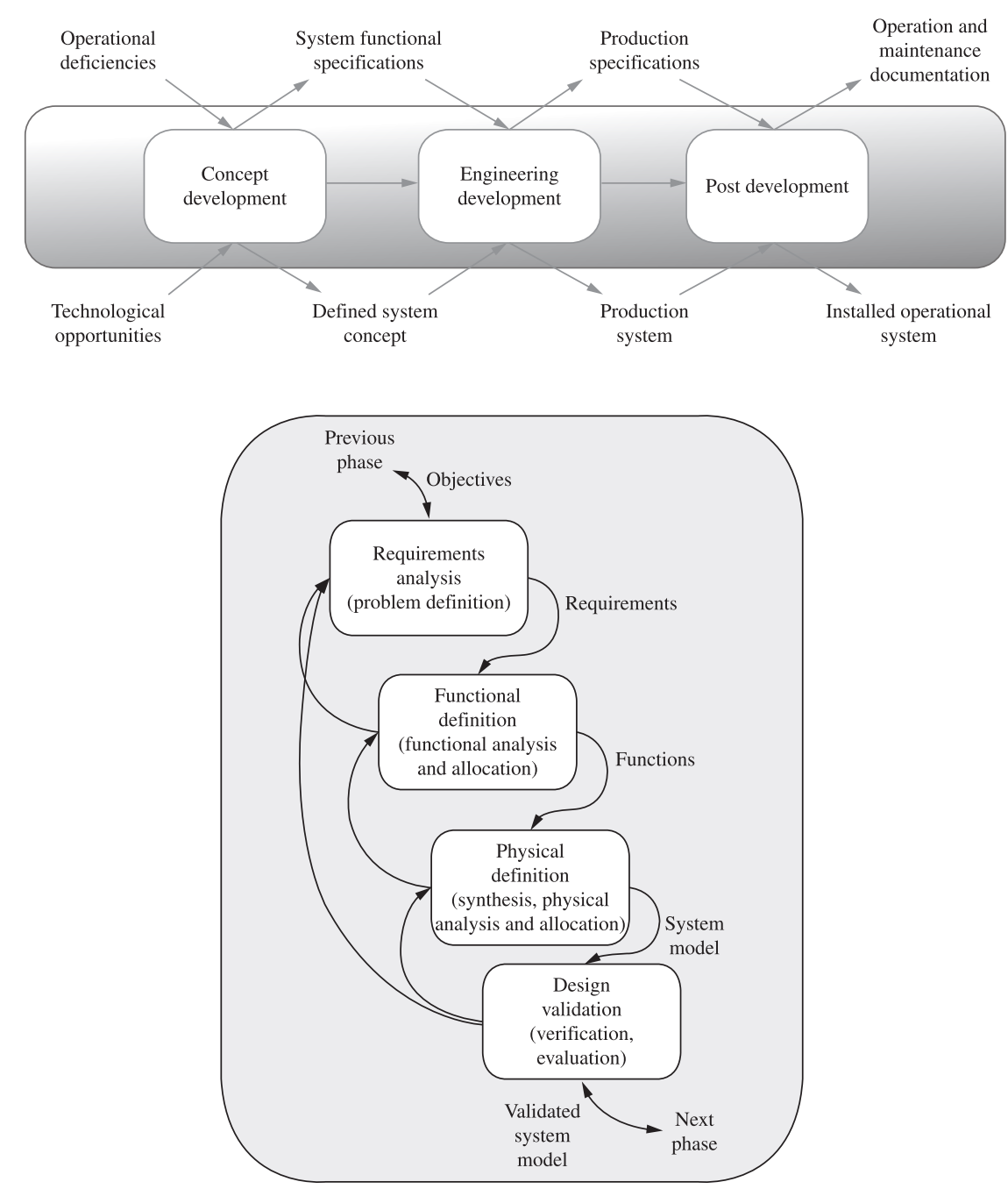

Figure 3. Other Models - Source: Kar and Bailey (1996). 


\section{Functions}

Once all goals to be achieved are defined (Section 1), the development of the functions that must be performed in the project shall be done. To develop functions it is useful to define the context expected for the system. The physical architecture definition comes naturally after the identification of the functions needed to perform all purposed objectives.
Example: A nano satellite CubeSAT must be ejected by its pod P-POD and the information must be sent to the students. Table 1 show the process of defining MOEs from objective. The Figure 4 shows the functional context diagram, used to define functions, and then the Figure 5 shows the functions itselves.

Therefore, the Systems Engineer must develop the ability to allocate such functions that will collaborate in the achievement of objectives.

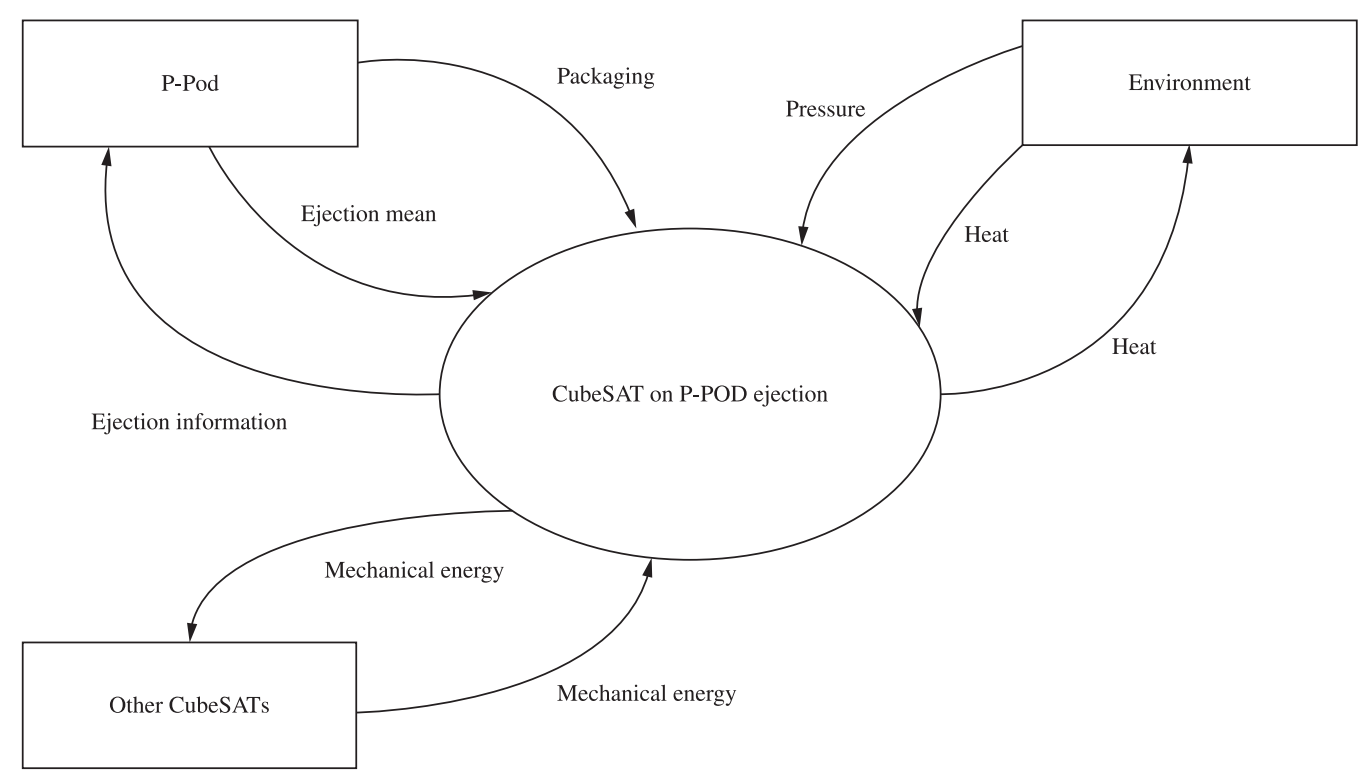

Figure 4. CubeSAT on P-POD ejection scenario - functional context diagram.

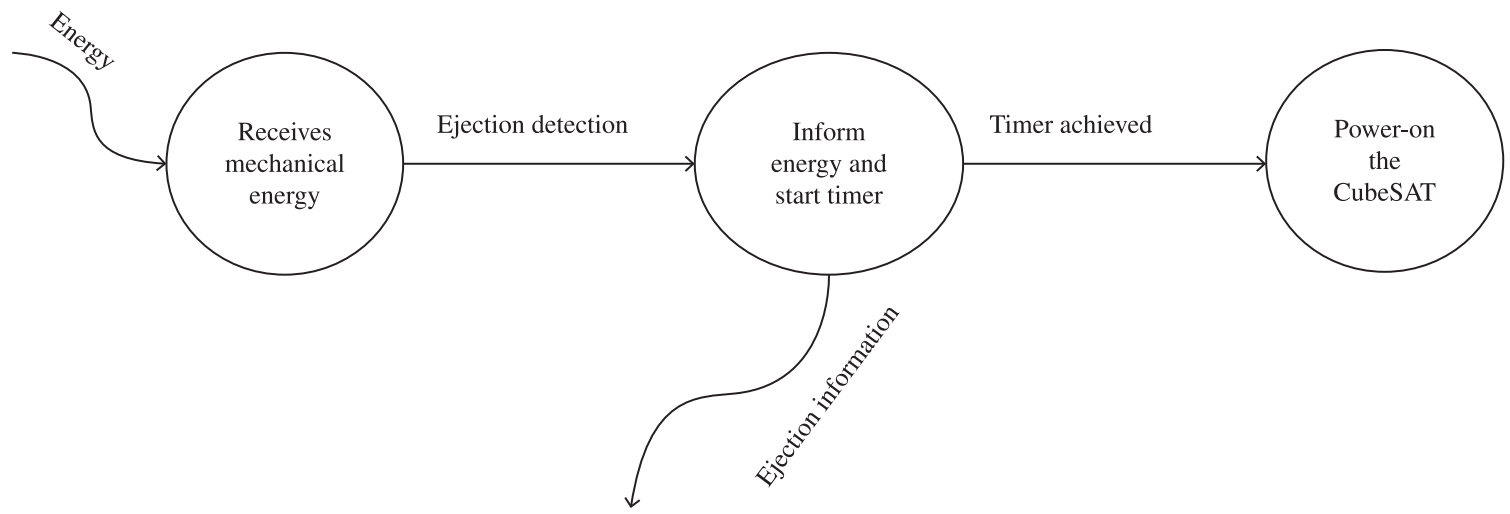

Figure 5. CubeSAT main functions in ejection scenario.

Table 1. Objective derivation example.

\begin{tabular}{|c|c|c|}
\hline Objective & Goal & MOE \\
\hline \multirow{2}{*}{$\begin{array}{l}\text { There is the necessity } \\
\text { of the CubeSAT to be } \\
\text { ejected }\end{array}$} & \multirow{2}{*}{$\begin{array}{l}\text { Students must receive the } \\
\text { ejection information in the } \\
\text { time expected }\end{array}$} & $\begin{array}{l}\text { The information is sent inside the time interval } \mathrm{X} \pm \text { error } 1 \text { by the vehicle }=\text { ideal } \\
\text { The information is sent inside the time interval } \mathrm{X} \pm \text { error } 2 \text { by the } \\
\text { vehicle = acceptable } \\
\text { The information is sent inside the time interval } \mathrm{X} \pm \text { error } 3 \text { by the } \\
\text { vehicle = unacceptable }\end{array}$ \\
\hline & & $\begin{array}{l}\text { The information is sent inside the time interval } \mathrm{Y} \pm \text { error } 1 \text { by CubeSAT }=\text { ideal } \\
\text { The information is sent inside the time interval } \mathrm{Y} \pm \text { error } 2 \text { by CubeSAT }=\text { acceptable } \\
\text { The information is sent inside the time interval } \mathrm{Y} \pm \text { error } 3 \text { by CubeSAT }=\text { unacceptable }\end{array}$ \\
\hline
\end{tabular}


Proposed goals must be related to one or more functions required for its realization, see Table 2 as a Requisites Allocation Matrix, it's the tool used to relate proposed goals to functions.

\section{Physical architecture and allocation}

From physical architectures, we obtain the alternatives of hardware and software, closing the Systems Engineering process. To implement the functions, it is needed to define the interfaces through physical architecture.

The Figure 6, shows an example of physical architecture definition through a physical architecture diagram.

Example: a nano-satellite CubeSAT in ejection of its pod P-POD scenario.
From this physical architecture, showed in Figure 6, we identify the interfaces between the several components of nano satellite CubeSat on ejection of its pod P-POD scenario and choose the way to implement it. We use the Interconnection Diagram in the Figure 7 to define those physical interfaces to be implemented.

After the definition of what kind of interfaces it will be used, it is necessary to define the details of this interfaces, the N2 diagram, Table 3, shows every interface in the system, each block in this diagram is one interface. For each interface it is necessary a document, the Interface Control Document which defines the interfaces in the project and assure that all components and/or sub-system will be developed in a way to interconnect themselves in a way to be possible to change energy, information or matter.

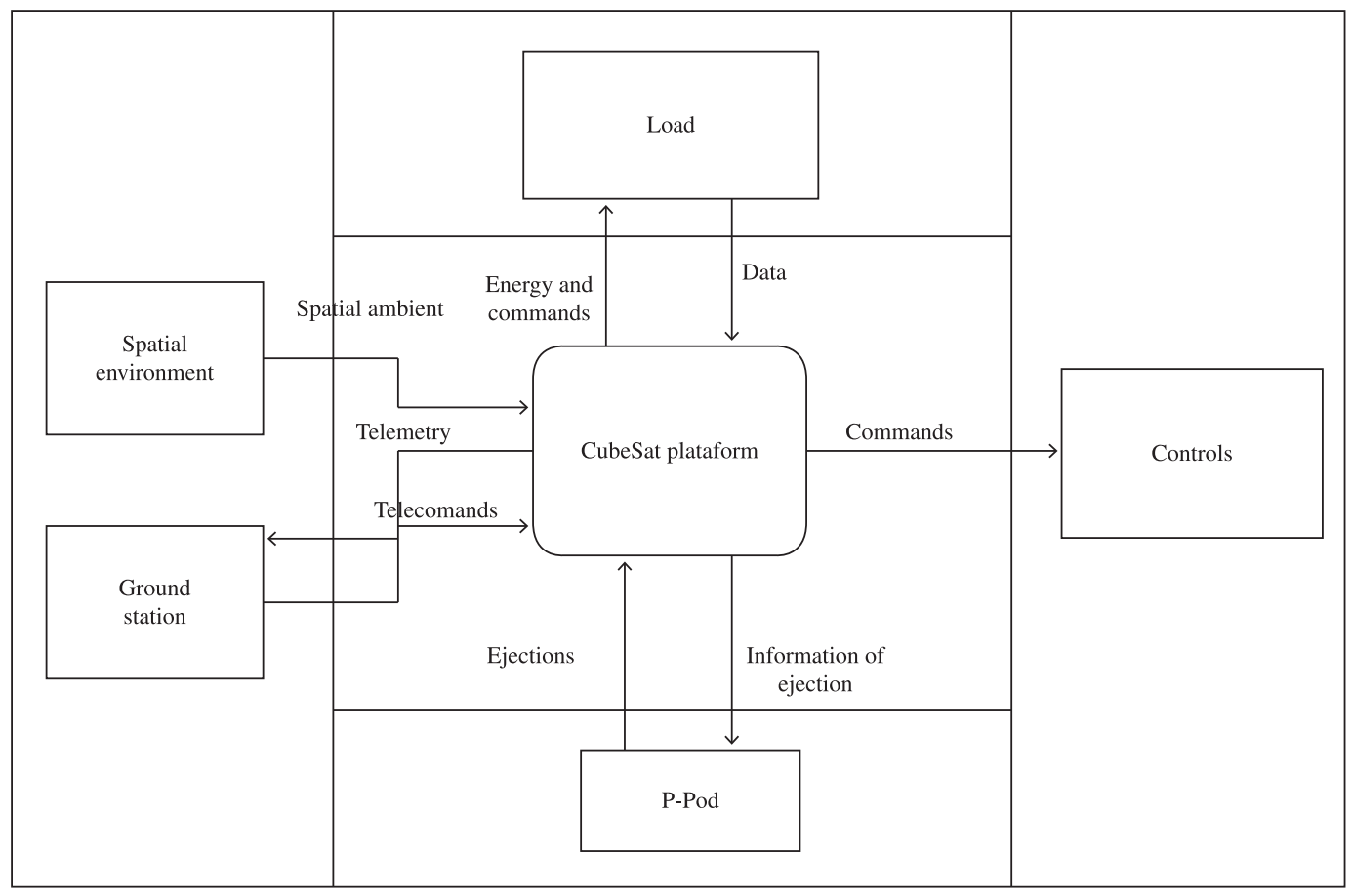

Figure 6. Physical architecture diagram - CubeSAT Satellite Example.

Table 2. Requisites Allocation Matrix.

\begin{tabular}{|c|c|c|c|c|c|c|}
\hline Sunction & Structure & Energy supply & $\begin{array}{c}\text { Thermal } \\
\text { control }\end{array}$ & $\begin{array}{c}\text { Board } \\
\text { management }\end{array}$ & Telecom & $\begin{array}{c}\text { Atitude } \\
\text { control }\end{array}$ \\
\hline Receive mechanical energy & $\mathrm{X}$ & & & & & \\
\hline Detect ejection & $\mathrm{X}$ & & & $\mathrm{X}$ & & \\
\hline Timer & & $\mathrm{X}$ & & $\mathrm{X}$ & & \\
\hline Power-on CubeSat & & $\mathrm{X}$ & & $\mathrm{X}$ & & \\
\hline Heat exchange & $\mathrm{X}$ & & $\mathrm{X}$ & & & \\
\hline Receive energy & & $\mathrm{X}$ & & & & \\
\hline Receive command & & & & $\mathrm{X}$ & $\mathrm{X}$ & \\
\hline Send data & & & & $\mathrm{X}$ & $\mathrm{X}$ & \\
\hline Atitude correction & & & & $\mathrm{X}$ & & $\mathrm{X}$ \\
\hline Mechanical interfaces & $\mathrm{X}$ & & & & & \\
\hline
\end{tabular}




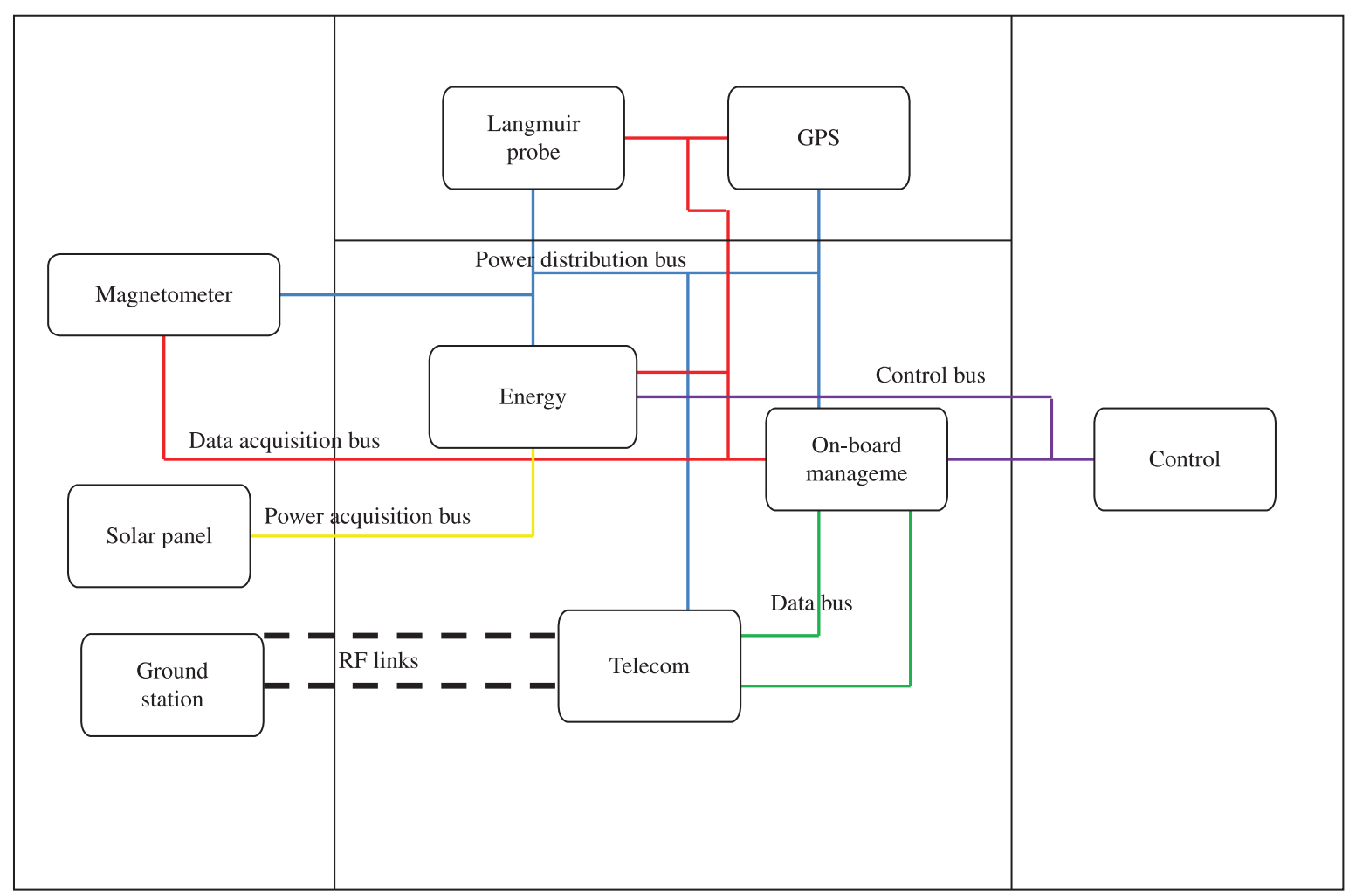

Figure 7. Architecture Interconnection Diagram - CubeSAT example.

Table 3. N2 Diagram - Nano Satellite CubeSAT in ejection from the P-POD scenario.

\begin{tabular}{|c|c|c|c|c|c|c|c|c|c|c|}
\hline & 1 & 2 & 3 & 4 & 5 & 6 & 7 & 8 & 9 & 10 \\
\hline 1 & Environment & $\begin{array}{l}\text { Magnetic } \\
\text { Field }\end{array}$ & Plasma & & & Sunlight & & & & \\
\hline \multirow[b]{2}{*}{2} & & \multirow[b]{2}{*}{ Magnetômetro } & & & & & & & & \\
\hline & & & & & & & & & $\begin{array}{l}\text { D.Aq. } \\
\text { Bus }\end{array}$ & \\
\hline \multirow[b]{2}{*}{3} & & & \multirow{2}{*}{$\begin{array}{c}\text { Sonda } \\
\text { Langmuir }\end{array}$} & & & & & & Data & \\
\hline & & & & & & & & & $\begin{array}{l}\text { D.Aq. } \\
\text { Bus }\end{array}$ & \\
\hline \multirow[b]{2}{*}{4} & & & & \multirow[b]{2}{*}{ GPS } & & & & & Data & \\
\hline & & & & & & & & & $\begin{array}{l}\text { D.Aq. } \\
\text { Bus }\end{array}$ & \\
\hline \multirow[b]{2}{*}{5} & & Power & Power & Power & \multirow{2}{*}{$\begin{array}{l}\text { Power } \\
\text { Supply }\end{array}$} & & & Power & Power & \\
\hline & & $\begin{array}{l}\text { Power Dist. } \\
\text { Bus }\end{array}$ & $\begin{array}{c}\text { Power } \\
\text { Dist. Bus }\end{array}$ & $\begin{array}{c}\text { Power } \\
\text { Dist. Bus }\end{array}$ & & & & $\begin{array}{c}\text { Power Dist. } \\
\text { Bus }\end{array}$ & $\begin{array}{c}\text { Power } \\
\text { Dist. Bus }\end{array}$ & \\
\hline \multirow[b]{2}{*}{6} & & & & & Energy & \multirow[b]{2}{*}{ SolarPanel } & & & & \\
\hline & & & & & $\begin{array}{l}\text { Power } \\
\text { Aq. Bus }\end{array}$ & & & & & \\
\hline \multirow{2}{*}{7} & & & & & & & Estação de & Telecomandos & & \\
\hline & & & & & & & Solo & RF Links & & \\
\hline \multirow{2}{*}{8} & & & & & & & Telemetrias & \multirow{2}{*}{ Telecom } & Dados & \\
\hline & & & & & & & RF Links & & Data Bus & \\
\hline \multirow{2}{*}{9} & & & & & Commands & & & Data & \multirow{2}{*}{$\begin{array}{c}\text { Gestão de } \\
\text { Bordo }\end{array}$} & Comandos \\
\hline & & & & & Ctrl. Bus & & & Data Bus & & Ctrl. Bus \\
\hline 10 & & & & & & & & & & Controle \\
\hline
\end{tabular}




\section{Conclusions}

Even if the Systems Engineer uses the methods of Systems Engineering to identify all the stakeholders, their concerns, their goals, measures of effectiveness and performance to assess how the project meets the requirements. Even with these methods, the Engineer can implement the functions necessary to achieve the objectives, developing an architecture for the product and an architecture for the organization, the final solution of product and organization may not be ideal due to several other problems as:

- Failure to use common sense to the members of a particular part of the solution, or a certain level of abstraction;

- Failure in modeling a real solution, be it product or organization, or both;

- Failure to exchange information among developers, who have their own objectives that may conflict in certain period of existence of the solution; and

- Failure to use outdated technology or yet to be developed.

Thus, it is therefore necessary to generate at least one solution comprising product and organization in addition to satisfying only the initial requirements of the stakeholders, actual requirements derived from existing technological condition during the lifetime of the solution, ie, if the problem to be solved could applied in the future, solutions to be presented by the Systems Engineer should make use of technologies that will be developed and used in the future, understanding by future a time definite and known at present, while the solution is being developed.

\section{References}

INTERNATIONAL COUNCIL ON SYSTEMS ENGINEERING - INCOSE. What is Systems Engineering? 2011. Disponível em: <http://www.incose.org/practice/ whatissystemseng.aspx>. Acesso em: 23 nov. 2011.

KAR, P.; BAILEY, M. Characteristics of Good Requirement. In: INTERNATIONAL SYMPOSIUM OF THE INCOSE, 6., 1996. Proceedings... INPE, 1996. v. 2, p. 284-291. Disponível em: <http://mb294.lit.inpe. br/se2012/6_requirements/Characteristics of Good Requirement.pdf $>$.

KELLER, L. R.; KIRKWOOD, C. W.; JONES, N. S. Assessing Stakeholder Evaluation Concerns: an application to the Central Arizona Water Resources System. Systems Engineering, v. 13, n. 1, p. 58-71, 2010. http://dx.doi. org/10.1002/sys.20132

PROJECT MANAGEMENT BODY OF KNOWLEDGE - PMBOK. A Guide to the Project Management Body of Knowledge. 4th ed. Project Management Institute - PMI, 2008. 